\title{
Lipid Oxidation of Salted Freeze-Dried Fish Meats at Different Equilibrium Relative Humidities
}

\author{
Chiaki Kolzum**, Hisaaki Terashmi*, Shun WADA*, and Junsaku NonAKA* \\ (Received February 25, 1980)
}

\begin{abstract}
The rates of lipid oxidation of salted freeze-dried bluefin tuna and sablefish meats, as model of salted dried fish products, were investigated as a function of moisture equilibrium relative humidity at $25^{\circ} \mathrm{C}$.

The lipid oxidation in the salted freeze-dried bluefin tuna proceeded rapidly at all relative humidities tested (ranging from 0 to $71 \%$ ) during storage, resulting in the considerable loss of polyenoic acids; the rates of oxidative destruction of polyenoic acids were higher at lower relative humidity. The oxidative destructions of some of monoenoic acids were also found in the lipids of salted freezedried bluefin tuna.

On the other hand, the lipids in salted freeze-dried sablefish were stable to oxidative destruction, even at lower relative humidity such as $11 \% \mathrm{RH}$ corresponding to the monomolecular layer of water. No changes were found in the percentages of polyenoic and monoenoic acids in the total lipids of salted freeze-dried sablefish during storage. However, the lipids were hydrolyzed enzymatically at higher relative humidity such as $71 \% \mathrm{RH}$.
\end{abstract}

It is well known that the rates of oxidative deterioration of lipids in food during storage closely relate to the relative humidity of atmosphere in which the food is stored ${ }^{13}$. In the previous paper ${ }^{23}$, it has been reported that the rate of lipid oxidation in the freeze-dried big-eye tuna, a typical red muscle fish, is higher at lower relative humidity during storage, while the freeze-dried halibut, a typical white muscle fish, scarcely undergoes lipid oxidation during storage, even at low relative humidity.

Salted dried fish products are considered more susceptible to oxidative deterioration than the dried fish products such as above-mentioned freezedried tuna and halibut meats, because the added $\mathrm{NaCl}$ is known to have a strong prooxidant effect on lipids, though the mechanism of lipid oxidation catalyzed by $\mathrm{NaCl}$ is not fully understood.

In this study, the rates of lipid deterioration of salted freeze-dried meats of bluefin tuna, red muscle fish, and sablefish, white muscle fish, were investigated as a function of moisture equilibrium relative humidity in order to search the storage conditions suitable for salted dried fish products.

\section{Experimental}

\section{Preparation of Samples}

The muscle of bluefin tuna, Thunnus thynnus, was sliced into $5 \mathrm{~mm}$ slabs, soaked in $5 \% \mathrm{NaCl}$ solution for 30 minutes, and freeze-dried. After freeze-drying, the skin and dark muscle were removed and the ordinary muscle was ground into coarse powder in a mortar. The sample of sablefish, Anopoploma fimbria, was prepared in the same manner.

\section{Storage Conditions of Samples}

The storage conditions used are the same as those in the previous paper ${ }^{2)}$. About $20 \mathrm{~g}$ portions of the sample were spread in petri dishes $(15.5 \mathrm{~cm}$ in diameter), which were held at $25^{\circ} \mathrm{C}$ in the desiccators (22 cm in diameter) equilibrated to the relative humidities $(\mathrm{RH})$ of $0,11,52$, and $71 \%$ by means of phosphorus pentoxide and the saturated solutions of lithium chloride, magnesium nitrate, and strontium chloride ${ }^{33}$, respectively. At appropriate intervals during storage, the moisture content and peroxide value (POV) of the samples were determined. The lipids were also extracted from the samples for analysis of fatty acid compositions.

\section{Determinations of Moisture Content and POV}

Moisture content of samples was determined using a Karl Fisher Moisture Automatic Titrator, Tsutsui Rikagaku Kikai Co., LTD. POV were measured by the method described by BARTHEL and $\mathrm{GROSCH}^{4}$.

\footnotetext{
* Tokyo University of Fisheries, 5-7, Konan-4, Minato-ku, Tokyo 108 (小泉千秋・寺島久明・和田 俊・ 野中洞三九: 東京水産大学).
} 
Extraction, Fractionation, and Analysis of Lipids

Extraction, fractionation, and analysis of fatty acid composition of lipids were carried out by the same methods as in the previous study ${ }^{2}$.

\section{Results and Discussion}

\section{Water Sorption Isotherms}

Water sorption isotherms of salted freeze-dried bluefin tuna meat and sablefish meat prepared at $25^{\circ} \mathrm{C}$ are shown in Fig. 1. For the purpose of preparing the water sorption isotherms, the desiccators equilibrated to various relative humidities by means of different concentrations of sulfuric acid were used. From the BET equation, the moisture contents of samples corresponding to the monomolecular layer of water were calculated to be $5.4 \mathrm{~g} \mathrm{H}_{2} \mathrm{O} / 100 \mathrm{~g}$ dry solids at $10.3 \% \mathrm{RH}$ for bluefin tuna and $2.4 \mathrm{~g} \mathrm{H}_{2} \mathrm{O} / 100 \mathrm{~g}$ dry solids at $11.1 \%$ RH for sablefish. The values are different from those reported for fish meats so far; $5.2 \mathrm{~g}$ $\mathrm{H}_{2} \mathrm{O} / 100 \mathrm{~g}$ dry solids at $18.5 \% \mathrm{RH}$ for freezedried big-eye tuna ${ }^{2)}, 6.5 \mathrm{~g} \mathrm{H}_{2} \mathrm{O} / 100 \mathrm{~g}$ dry solids at $21.0 \% \mathrm{RH}$ for freeze-dried halibut ${ }^{2)}$, and $5 \mathrm{~g}$ $\mathrm{H}_{2} \mathrm{O} / 100 \mathrm{~g}$ dry solids at $19 \% \mathrm{RH}$ for freeze-dried salmon ${ }^{5)}$. This may be due to added $\mathrm{NaCl}$; $\mathrm{NaCl}$ contents of salted freeze-dried bluefin tuna and sablefish were 10.2 and $9.9 \%$ on dry basis, respectively.

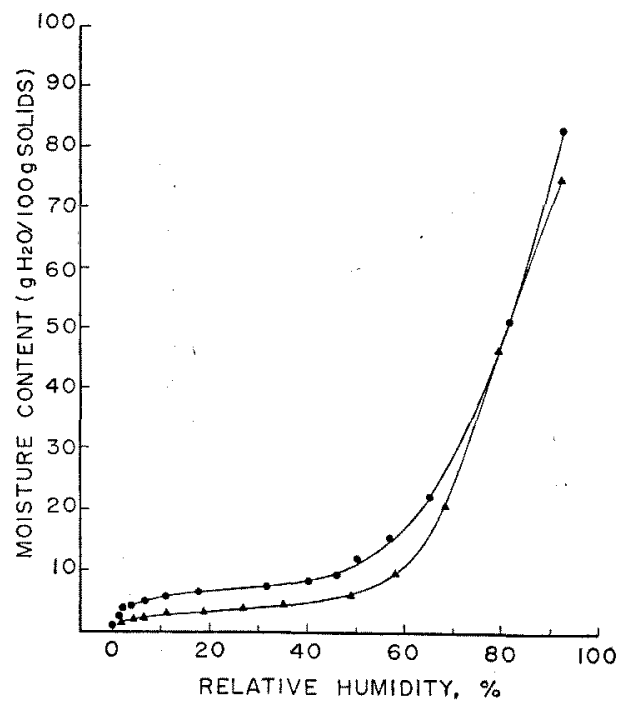

Fig. 1. Water sorption isotherms of salted freeze-

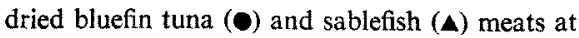
$25^{\circ} \mathrm{C}$.

\section{Changes in Moisture Contents}

At appropriate intervals, the moisture contents of the samples were determined and are shown in Fig. 2. The moisture contents of all samples became almost constant within 7 days of storage. The samples of bluefin tuna and sablefish used in this experiment contained $7.3 \%$ and $7.2 \% \mathrm{NaCl}$ on dry basis, respectively.

\section{Changes in $\mathrm{POV}$}

Changes in POV of salted freeze-dried bluefin tuna during storage are shown in Fig. 3. The POV

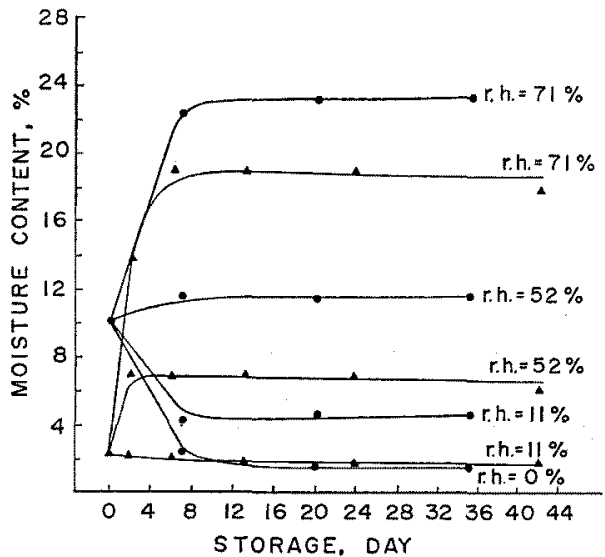

Fig. 2. Changes in the moisture contents of salted

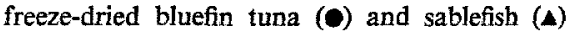
meats during storage at different relative humidities indicated in the figure.

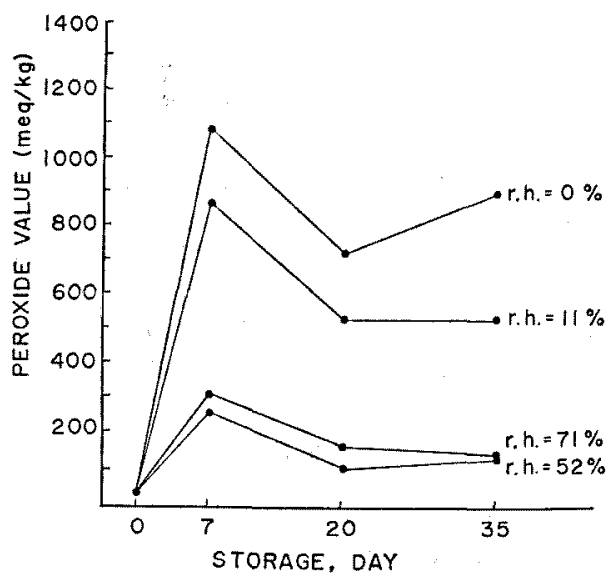

Fig. 3. Changes in the POV of salted freeze-dried bluefin tuna meat during storage at different relative humidities indicated in the figure. 
Table 1. Fatty acid compositions of the lipids of salted freeze-dried bluefin tuna and sablefish meats before storage $(\%)$

\begin{tabular}{|c|c|c|c|c|c|c|c|c|}
\hline \multirow{2}{*}{ Fatty acid } & \multicolumn{4}{|c|}{ Bluefin tuna } & \multicolumn{4}{|c|}{ Sablefish } \\
\hline & TL & PL & TG & FFA & $\mathrm{TL}$ & PL & $\mathrm{TG}$ & FFA \\
\hline $14: 0$ & 3.6 & 2.2 & 3.6 & 3.1 & 4.1 & 1.3 & 4.0 & 3.3 \\
\hline $15: 0$ & 0.7 & 0.6 & 0.8 & 0.8 & - & 0.2 & 0.3 & - \\
\hline $16: 0$ & 24.4 & 28.1 & 20.5 & 23.6 & 16.1 & 18.5 & 16.4 & 20.6 \\
\hline $16: 1$ & 5.0 & 2.3 & 4.4 & 4.6 & 8.7 & 2.7 & 8.4 & 9.6 \\
\hline $16: 2$ & - & - & - & - & 0.7 & - & 0.5 & 0.6 \\
\hline $17: 0$ & 1.8 & 1.2 & 1.4 & 1.3 & - & - & - & - \\
\hline $18: 0$ & 9.7 & 14.8 & 8.3 & 19.1 & 2.5 & 5.1 & 2.2 & 3.8 \\
\hline $18: 1$ & 32.3 & 17.9 & 29.4 & 26.7 & 31.8 & 15.9 & 32.9 & 35.9 \\
\hline $18: 2$ & 1.7 & 1.8 & 1.6 & 1.3 & 1.2 & 0.9 & 1.1 & 1.5 \\
\hline $18: 3$ & 1.2 & - & 1.1 & 0.7 & 0.1 & - & 0.2 & 0.2 \\
\hline $18: 4$ & - & - & - & - & 1.3 & 0.4 & 1.2 & - \\
\hline $20: 0$ & trace & 0.6 & trace & 0.8 & - & 0.3 & - & - \\
\hline $20: 1$ & 5.4 & 1.8 & 5.4 & 3.7 & 13.8 & 8.7 & 13.1 & 9.0 \\
\hline $20: 2$ & - & 0.5 & - & - & - & 0.1 & 0.3 & - \\
\hline $20: 4$ & 1.0 & trace & 1.0 & 0.9 & - & 1.5 & 0.4 & - \\
\hline $20: 5$ & 3.0 & 6.3 & 4.1 & 3.8 & 5.4 & 9.4 & 5.1 & 6.0 \\
\hline $22: 1$ & 1.3 & 4.4 & 1.5 & - & 8.7 & 9.8 & 9.0 & 5.0 \\
\hline $22: 4$ & - & - & - & - & 0.2 & 0.2 & 0.3 & 0.7 \\
\hline $22: 5$ & - & 0.8 & - & - & 0.8 & 1.8 & 0.7 & - \\
\hline $22: 6$ & .7 .8 & 14.8 & 13.8 & 8.8 & 3.3 & 19.8 & 2.7 & 3.2 \\
\hline $24: 0$ & - & trace & 1.2 & 0.8 & - & - & - & - \\
\hline $24: 1$ & 1.0 & 1.0 & 1.9 & trace & 0.9 & 2.9 & 1.1 & - \\
\hline Sat.* & 40.2 & 48.4 & 35.8 & 49.5 & 22.7 & 25.4 & 22.9 & 27.7 \\
\hline Mono.* & 45.0 & 27.4 & 42.6 & 35.0 & 63.9 & 40.0 & 64.5 & 59.5 \\
\hline Poly.* & 14.7 & 24.2 & 21.6 & 15.5 & 13.3 & 34.6 & 12.5 & 13.0 \\
\hline
\end{tabular}

- Sat., Saturated acid; Mono., Monoenoic acid; Poly., Polyenoic acid.

of samples stored at 0 and $11 \% \mathrm{RH}$ increased markedly during the first 7 days of storage and then decreased. At 52 and $71 \% \mathrm{RH}$, the POV also increased to some extent after 7 days and thereafter decreased gradually.

The POV of sablefish samples increased to some extent at $11 \% \mathrm{RH}$ and slightly at 52 and $71 \%$ RH up to 42 days of storage, as shown in Fig. 4. The degree of increases in POV of sablefish, even at $11 \% \mathrm{RH}$, was considerably lesser than those of bluefin tuna.

\section{Fatty Acid Compositions of Lipids}

Fatty acid compositions of the lipids in salted freeze-dried bluefin tuna and sablefish before storage are shown in Table 1. The total lipids (TL) of bluefin tuna and sablefish contained monoenoic acid at highest proportion. Percentages of polyenoic acid were similar in both fishes, though the percentage of $\mathrm{C}_{22: 0}$ acid in the TL fraction of bluefin tuna was approximately twice that of sablefish.

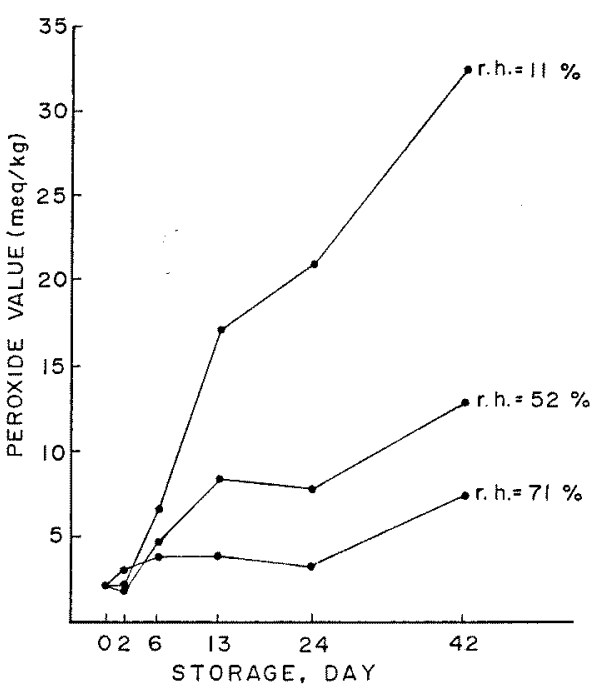

Fig. 4. Changes in the POV of salted freeze-dried sablefish meat during storage at different relative humidities indicated in the figure. 
Changes in Percentages and Fatty Acid Compositions of Lipid Classes

1. Salted freeze-dried bluefin tuna: The bluefin tuna meat used in this study contained $19.0 \%$ total lipid on dry basis consisting of about $87 \%$ triglyceride fraction (TG), $8.8 \%$ polar lipid fraction (PL), and $4.6 \%$ free fatty acid fraction (FFA). Influences of relative humidities on the percentages of TG, PL, and FFA fractions of the lipids during storage are shown in Fig. 5.

At $0 \% \mathrm{RH}$, the percentage of TG in the bluefin tuna lipids decreased considerably accompanied by marked increases in the PL fraction after 7 days of storage. Thereafter, the TG and PL fractions remained almost unchanged up to 35 days. There was no significant change in the FFA fraction until the end of the storage period. A similar pattern of changes in percentages of lipid classes was found at $11 \% \mathrm{RH}$. The marked increase in the PL fraction after 7 days suggests that the oxidation of some of triglycerides occurred, because the oxidized triglycerides might be separated into the PL fraction by column chromatography on Bio-Beads SX 2 due to their enhanced polarity.

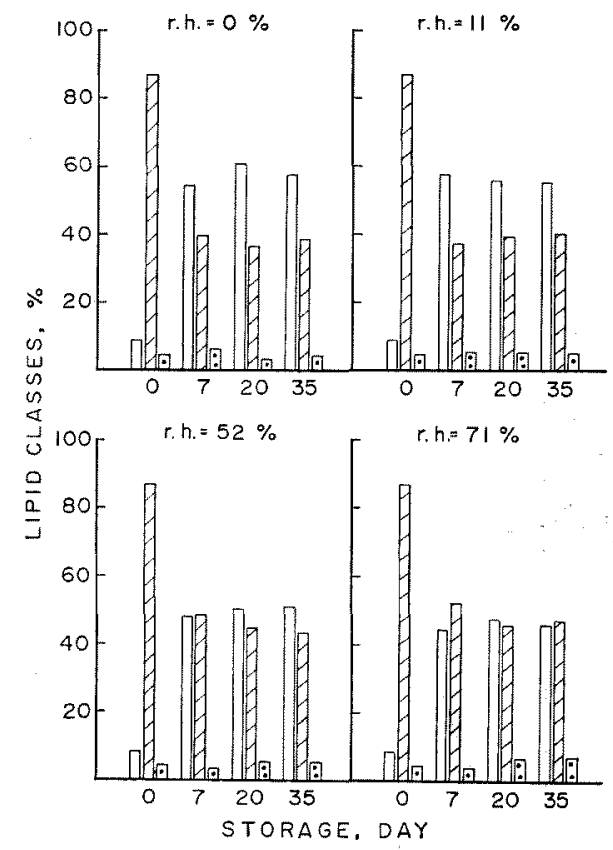

Fig. 5. Influences of the relative humidities (indicated in the figure) on the percentages of lipid classes in salted freeze-dried bluefin tuna during storage. $\square, \mathrm{PL}$ fraction; $\oslash$, TG fraction; $\square$, FFA fraction.
Similarly, at higher relative humidities, 52 and $71 \%$ $\mathrm{RH}$, the TG fraction decreased accompanied by increase in the PL fraction after 7 days, though the changes occurring in the TG and PL fractions were not so marked as those at 0 and $11 \% \mathrm{RH}$.

These results suggest that at all relative humidities tested the lipids in salted freeze-dried bluefin tuna undergo oxidation considerably not only in the PL fraction but also in the TG fraction during the first 7 days of storage and that the oxidation of lipids proceeds more rapidly at lower relative humidities than at higher relative humidities. The slight increase in FFA fraction at $71 \% \mathrm{RH}$ in the later stage of storage seems to be due to both oxidative degradation of unsaturated lipids and hydrolysis of lipids with endogenous enzyme system in the meat.

Changes in the fatty acid compositions of the lipids during storage are shown in Figs. 6 and 7. In the figures, the fatty acid compositions of lipids were expressed as relative amounts of three groups of fatty acids, saturated, monoenoic, and polyenoic acids.

At $0 \% \mathrm{RH}$, the polyenoic acid was almost completely lost from all lipid fractions of the bluefin tuna due to oxidative destruction during storage. The ratios of the percentages of monoenoic acid to those of saturated acid in the TG and TL frac-

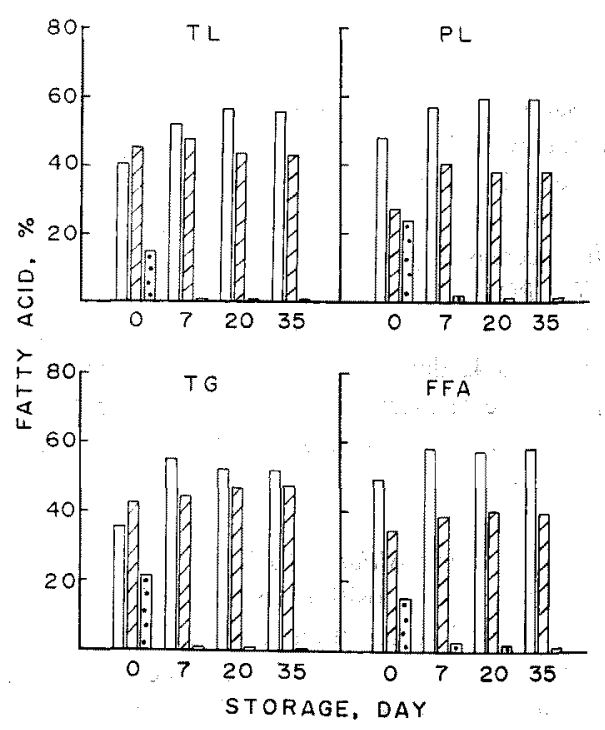

Fig. 6. Changes in the fatty acid compositions of the lipid classes in salted freeze-dried bluefin tuna during storage at the relative humidity of $0 \%$. $\square$, saturated acid; $\square$, monoenoic acid; $\square$, polyenoic acid. 


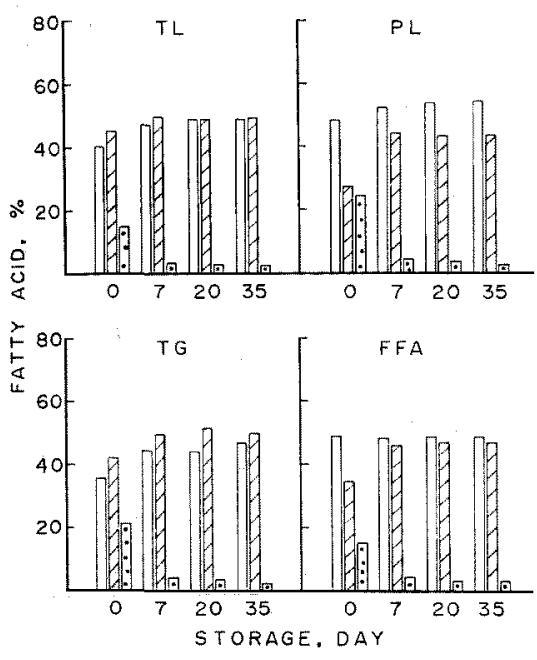

Fig. 7. Changes in the fatty acid compositions of the lipid classes in salted freeze-dried bluefin tuna during storage at the relative humidity of $52 \%$. See the legend of Fig. 6.

tions decreased markedly during storage, suggesting the oxidation of monoenoic acid in the $T G$ fraction to occur. Similar results were obtained at $11 \% \mathrm{RH}$, though the data are not shown here.

At $52 \% \mathrm{RH}$, the percentage of polyenoic acid also decreased in all lipid classes during storage, though the decreases of polyenoic acid were not so marked as those found at $0 \% \mathrm{RH}$. Slight decreases in the ratios of the monoenoic acid to the saturated acid were found in the $T G$ and $T L$ fractions. Similar pattern of changes in fatty acid composition was observed at $71 \% \mathrm{RH}$, though the data are not shown here.

These results indicate that the influences of relative humidities on the rate of lipid oxidation in salted freeze-dried bluefin tuna during storage are similar to those found in the freeze-dried big-eye tuna, as previously reported ${ }^{2}$, which does not contain added $\mathrm{NaCl}$ and that the rate of lipid oxidation is extremely higher in the salted bluefin tuna than in the big-eye tuna at all relative humidi. ties tested.

These results are different from those reported by LABuzA et $a l^{6}{ }^{6}$, that is, the rate of oxygen uptake of chicken system is twice as fast at water activity of 0.75 as at 0.1 . Similar phenomenon has also been found in pork system ${ }^{7)}$. These workers have postulated that the higher rate of oxygen uptake at higher water activity is due to oxidation of lipids catalyzed by a trace amount of metal in the systems. On the other hand, MizuSHIMA et al ${ }^{83}$ have reported that the oxidation rate of model system consisting of fish oil and egg albumin is higher at $32 \% \mathrm{RH}$ than at $75 \% \mathrm{RH}$ and that neither hemin nor $\mathrm{Fe}^{8+}$ added to the model system as catalysts show influence on the oxidation pattern of lipids, though $\mathrm{Cu}^{2+}$ exhibits the influence on the rate of lipid oxidation, resulting in the prolonged induction period at $32 \% \mathrm{RH}$.

As discussed previously ${ }^{2)}$, the rate of lipid oxidation seems to be affected by various constituents as well as water in the system.

2. Salted freeze-dried sablefish: Changes in the percentages of lipid classes of the samples during storage are shown in Fig. 8. The sablefish meat used in this study contained $49.1 \%$ total lipids on dry basis consisting of TG, PL, and FFA fractions in the ratio of $93: 2.7: 4.5$.

At $11 \% \mathrm{RH}$, the percentage of $\mathrm{TG}$ fraction decreased gradually accompanied by the increase in PL fraction during 42 days of storage. The increase in PL fraction may be partly due to the oxidized triglycerides which behave as a polar lipid in the Bio-Beads column chromatography, as mentioned above. This implies that oxidation of TG fraction proceeds slowly during storage.

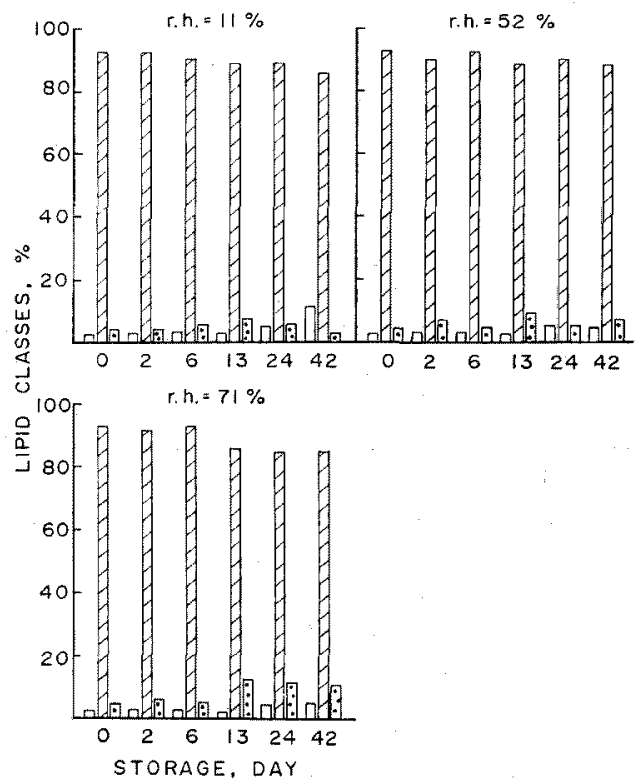

Fig. 8. Influences of the relative humidities (indicated in the figure) on the percentages of lipid classes in salted freeze-dried sablefish during storage. See the legend of Fig. 5 . 


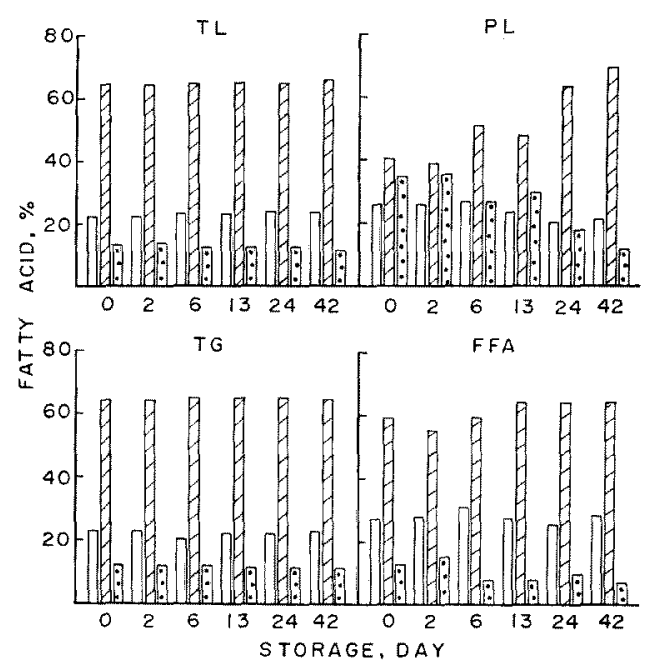

Fig. 9. Changes in the fatty acid compositions of the lipid classes in salted freeze-dried sablefish during storage at the relative humidity of $11 \%$. See the legend of Fig. 6 .

At $71 \% \mathrm{RH}$, the TG fraction also decreased in the later stage of storage. The decrease of TG fraction can be attributed not to oxidation but to hydrolysis of triglycerides. This is clear from the facts that the lipids in sample underwent only slight oxidation, as estimated by POV measurement, and that the FFA fraction increased to some extent, as shown in Fig. 8. The hydrolysis of TG fraction seems to be due to endogenous enzyme system in the meat. The samples stored at $52 \%$ RH seem to undergo both slight oxidation and hydrolysis of lipids during storage.

Changes in fatty acid composition of each lipid class during storage are shown in Figs. 9 and 10. No detectable change occurred in the fatty acid composition of TL and TG fractions in the samples stored at all relative humidities tested during 42 days of storage, though the data at $52 \% \mathrm{RH}$ are not shown. On the other hand, the fatty acid compositions of PL fractions changed markedly at all relative humidities tested; the polyenoic and saturated acids decreased and the monoenoic acid increased. The decrease in saturated acid and the increase in monoenoic acid of the PL fraction are difficult to be explained clearly. It is possible that the inclusion of some of triglycerides, which are rich in monoenoic acid, in the PL fraction as a result of incomplete separation in column chromatography affects the experimental results.

These results indicate that the lipids in salted

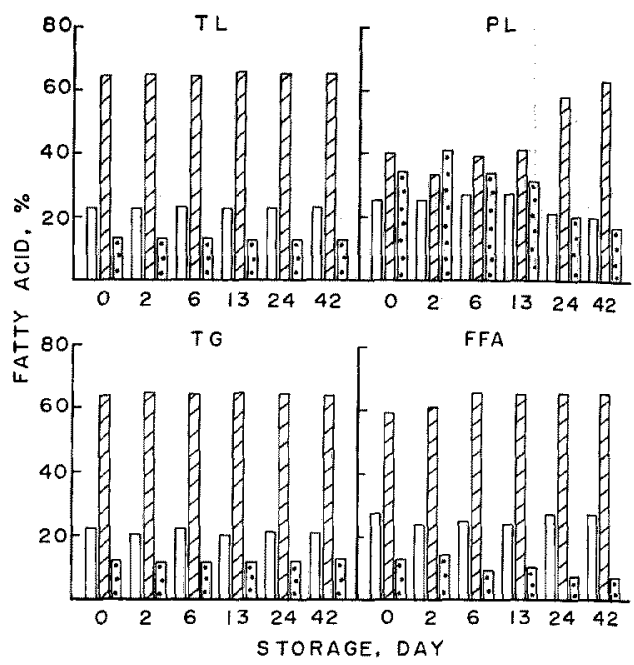

Fig. 10. Changes in the fatty acid compositions of the lipid classes in salted freeze-dried sablefish during storage at the relative humidity of $71 \%$. See the legend of Fig. 6.

freeze-dried sablefish, as compared with those in salted freeze-dried bluefin tuna, are considerably stable to oxidation. This could not be accounted for by the difference in the fatty acid composition of lipids between sablefish and bluefin tuna, since they contain polyenoic acids at similar proportion in their lipids. On the other hand, there is a marked difference in hemoprotein content between these two kinds of fishes; bluefin tuna contains hemoprotein at high concentration but sablefish at extremely low. Ellis et al. ${ }^{\text {) }}$ have reported that myoglobin and hemoglobin accelerates oxidation of lard in freeze-dried model system and that the heme catalysis of lard is further accelerated by added $\mathrm{NaCl}$. It is uncertain, however, whether hemoprotein is the only factor responsible for the different rate of lipid oxidation between the salted freeze-dried bluefin tuna and sablefish. Further study is necessary for better understanding the mechanisms of lipid oxidations in these salted freeze-dried fish meats.

This work was partly supported by a grant from the Ministry of Education.

\section{References}

1) T. P. LABUZA: in "Water Relations of Foods" (ed. by R. B. Duckworth), Academic Press, New York, 1975, pp 455-474. 
2) C. KoIzUMI, S. IrYAMA, S. WADA, and J. NONAKA: Bull. Japan. Soc. Sci. Fish., 44, 209-216 (1978).

3) L. B. Rockland: Anal. Chem., 32, 1375-1376 (1960).

4) G. Barthel and W. Grosch: J. Am. Oil Chemists' Soc., 51, 540-544 (1974).

5) F. Martinez and T. P. Labuza: J. Food Sci., 30, 241-247 (1968).

6) T.P. Labuza, M. Silver, M. Cohn, N. D.
Heidelbaugh, and M. Karel: J. Am. Oil. Chemists' Soc., 48, 527-531 (1971).

7) N. D. Heidelbaugh and M. Karel: J. Am. Oil Chemists' Soc., 47, 539-544 (1970).

8) Y. Mizushima, K. Takama, and K. Zama: Bull. Facul. Fish. Hokkaido Univ , 30, 163-171 (1979).

9) R. Ellis, A. M. Gaddis, G. T. Currie, and F. E. ThORNTON: J. Food Sci., 35, 52-56 (1970). 